\title{
A Pesquisa em Ética na Educação Ambiental ${ }^{1}$
}

\author{
Mauro Grün \\ Universidade do Planalto Catarinense
}

Resumo: Meu objetivo neste texto é traçar um panorama da pesquisa em ética ambiental salientando importantes insights e inspirações para a educação ambiental. Trata-se de estabelecer conexões entre a ética e a educação ambiental. O texto divide-se em três partes. Na primeira parte, demonstro como se deu o nascimento da ética ambiental como disciplina científica. Mostro isso a partir dos trabalhos de Routley (2003) e Naess (1995), ambos originalmente publicados em 1973. Routley argumenta que dentro da tradição ética ocidental dominante - os últimos 2.500 anos - não há lugar para a considerabilidade moral da Natureza. Esta só tem valor instrumental. No mesmo ano, Naess publicou sua plataforma da Ecologia Profunda com dezoito princípios que serviam de guia para a ação. A Ecologia Profunda advoga o bioigualitarismo biosférico, para o qual não existe hierarquia de valor entre as diferentes entidades da ecosfera - rochas, plantas, animais, rios, seres humanos e a terra como um todo -, ou seja, todas têm o mesmo valor, pelo menos do ponto de vista ético. $\mathrm{Na}$ segunda parte do texto, comento duas Éticas da Terra, a de Rolston (1996) e a de Callicott (1993). Rolston (1996) argumenta que a Natureza tem sido tratada quase exclusivamente como recurso natural. A mudança radical viria por meio de uma ética e de uma Educação Ambiental que passassem a admirar a Natureza em seus próprios termos. Para o filósofo, a frase "tudo é recurso" encontra paralelo na sentença "todo mundo é egoísta”. Callicott (1993), por sua vez, também apregoa uma Ética da Terra holista baseada em Darwin, David Hume e Adam Smith, defendendo o ecocentrismo. Seguindo Leopold (1987), Callicott (1993) argumenta que temos deveres morais para com a comunidade - terra. Esses deveres são baseados nos "sentimentos morais" de amor,

${ }^{1}$ Este texto é uma versão ampliada das discussões ocorridas no Grupo de Pesquisa em Ética e Epistemologia em Educação Ambiental, durante o III Encontro de Pesquisadores em Educação Ambiental (EPEA), ocorrido na Universidade de São Paulo (USP), Ribeirão Preto, em 2005. 
respeito, obrigação, admiração e pertença à terra. Argumento que as éticas do valor intrínseco contêm um grande potencial subversivo da ordem vigente. Ao final, proponho um casamento entre as diversas ecologias radicais como forma de empoderamento de educadores (as) ambientais.

Palavras-chave: Educação Ambiental. Ética Ambiental. Ecologia Radical.

Abstract: This papper offers an overview of the state of research in environmental ethics and explores the insights and inspiration such work provides into Envionmnetal Education. In short, the paper aims to establish a clear and detailed relationship between Environmental Ethics and Environmental Education. The essay is divided into three parts. In the first part, borrowing from the work of Routley (2003) and Naess (1995), I will trace and discuss the emergence of Environmental Ethics as a discipline (both works appeared initially in 1973). Routley proposes that within a hegemonic Western environmental tradition, that encompasses the last 2500 years, there has been no scope for an ethical engagement with Nature. Nature, he argues, has been seen purely in utilitarian terms. In the same year that Routley's work appeard, Naess also published his manifesto for Deep Ecology, with its 'eighteen principles for action'. Naess' Deep Ecology advocates the principle of a biospheric equality that does not distinguish among its various constitutive elements - rocks, plants, animals, rivers, human beings and the soil -, all being believed to have the same value, at least from an ethical viewpoint. Secondly, the paper will discuss two versions of Earth Ethics, notably those of Rolston (1996) and of Callicott (1993). In his work, Rolston (1996) argues that Nature has been seen exclusively as a natural resource. For Rolston, Environmental Education will play a radical role in the transformation of the way Nature is perceived. Such an approach will demand an engagement with Nature on its own terms, rather than within conventional utilitarian parameters. For this philosopher, the sentence 'everything is a resource' echoes the assertion that 'everyone is an egoist'. For his part, Callicott (1993) too defends a holistic Earth Ethics, an ecocentric approach rooted in the thought of Darwin, David Hume and Adam Smith. According to Leopold (1987), Callicott (1993) presumes that we all have a sense of ethical responsibility towards the community-Earth. This responsibilty is based on such 'ethical emotions' as love, respect, obligation, admiration for and belonging to the Land. For my part, then, I will posit that an ethics of intrinsic value has the potential to subvert the present status quo. Consequently, I will delineate how a strategic blending of the various radical ecology positions can lead to the empowerment of environmental educators.

Keywords: Environmental Education. Environmental Ethics. Radical Ecology 
A distinção entre Ética e Epistemologia é central para o projeto Iluminista. No entanto, após os trabalhos de Martin Heidegger e Hans-Georg Gadamer ao longo do séc. XX, essa distinção parece cada vez mais problemática. Neste texto, argumento que, na verdade, ética e epistemologia são indissociáveis, pois não se pode separar o saber dos valores. Assim, vou me ocupar de algumas tentativas de fundamentar uma ou várias éticas ambientais que poderiam fornecer alguns insights e inspirações importantes para a Educação Ambiental. A abordagem da dimensão ética da Educação Ambiental tem sido proposta por uma série de protocolos internacionais e tem também feito parte da agenda política do ambientalismo. Muitos ambientalistas e educadores (as) ambientais falam da necessidade de uma ética planetária ou global. Outros falam em diversas éticas ambientais regionais. Mas o fato indiscutível é que as questões éticas estão no centro dos debates. Ao longo deste texto, procuro mostrar um pouco da gênese da preocupação ambiental de cunho ético, fazendo um percurso argumentativo que parte do nascimento da ética ambiental como disciplina científica, seu desenvolvimento em várias partes do mundo e algumas das tendências atuais. $\mathrm{O}$ escopo da ética, dizem Light e Rolston (2003), é bem mais amplo que o da lei e diz respeito àquilo que é errado ou imoral, seja legal ou não. A ética ambiental disserta ou prescreve em que situações é imoral ou errado explorar, usar, dominar ou destruir a Natureza. Também se ocupa de quais as maneiras eticamente corretas de conservar, restaurar e estabelecer relações com a Natureza e com o mundo não-humano em geral. Algumas das correntes mais atuais da ética ambiental compreendem: o desafio da ética ambiental em relação ao antropocentrismo da tradição Ocidental; ética ambiental holista; ecologia profunda; ética ecocêntrica; ecologia social; ética ambiental feminista; éticas ambientais monistas; éticas ambientais pluralistas e perspectivas críticas em ética ambiental.

A ética ambiental como disciplina científica nasceu quase simultaneamente por dois desenvolvimentos independentes em 1973, um na Noruega, com Arne Naess (1995), e o outro na Austrália, com Richard Routley (2003). Em seu trabalho pioneiro Is There a Need for a New, an Environmental Ethic? (Existe a necessidade de uma nova ética, uma ética ambiental?), Routley (2003) inicia seu ensaio dizendo que a tradição ética Ocidental sanciona para que os 
seres humanos usem a Natureza ao seu bel-prazer. O importante na tradição ética dominante que remonta à Platão - 2.500 anos atrás é que você não faça mal ao outro, deixando a questão das relações humanas com o ambiente não tematizada e não sujeita à censura moral. Como diz Aldo Leopold, citado em Routley (2003), um fazendeiro que corta a madeira de $75 \%$ de sua terra e coloca suas vacas na área devastada, diminuindo, em conseqüência disso, as chuvas e causando a erosão, é considerado, apesar disso, um membro respeitável da sociedade. A esse princípio, Routley (2003) chama de Chauvinismo Humano Básico.

O chauvinismo humano básico consiste no fato de que a tradição Ocidental dominante tem tematizado unicamente as relações humanas. É uma ética intra-humana. Routley (2003) argumentou que as tradições éticas dominantes refletem um chauvinismo humano porque concedem apenas valor instrumental para as entidades não-humanas. Essas éticas foram incapazes de atribuir valor intrínseco à Natureza. Routley (2003) elabora um sofisticado experimento conceitual - que se tornou um clássico na literatura internacional - para defender a sua tese do chauvinismo humano. Ele nos pede para parar um momento e imaginar a seguinte situação, que é denominada "The last people" (As últimas pessoas): após um sério acidente em uma Usina Nuclear, os sobreviventes constatam que são as últimas pessoas sobre a Terra. Descobrem também que, devido ao efeito da radiação, eles perderam as capacidades reprodutivas e decidem devastar, extinguir espécies, atear fogo e destruir a Natureza deliberadamente. A pergunta que se coloca é se esses sobreviventes - as últimas pessoas - estão agindo corretamente do ponto de vista ético. A resposta de Routley (2003) é surpreendente. Ele diz que do ponto de vista ético não há o que censurar no comportamento dessas pessoas, pois, estando elas removidas de consideração moral às futuras gerações, a Natureza não é passível de ser tratada eticamente. A tradição ética dominante tematiza as relações de humanos para com humanos, sendo a Natureza considerada moralmente importante apenas indiretamente, somente quando tem um valor instrumental.

O trabalho de Routley (2003), juntamente com o do norueguês Arne Naess (1995), marca o início da ética ambiental como campo de pesquisa. O artigo de Naess (1973) The Shallow and 
the Deep, Long-Range Ecology Movement (O Superficial e o Profundo, o Longo Alcance do Movimento Ecológico), publicado originalmente no periódico Inquiry - primeiro do mundo a dedicar-se à ética ambiental -, transpôs o ambiente acadêmico, chegando ao movimento ecológico. Influenciado por Ghandi, pelo Budismo e por Spinoza, Naess (1993) cunhou o termo "Ecologia Profunda". Essa ecologia seria profunda pelo fato de ir às raízes da crise ecológica, enquanto a ecologia superficial se preocuparia apenas com medidas paliativas, como filtros para a poluição, etc. A Ecologia Superficial seria uma ética ambiental administrativa. O ecofilósofo argumenta que a maioria dos experts em Ecologia, Ecosofia ou ativistas do movimento ecológico estão na defensiva, não podendo revelar as verdadeiras causas da devastação ambiental, pois nesse caso não seriam ouvidos. São poucos os que conseguem, em seu trabalho, fazer uma avaliação filosoficamente fundamentada da crise ecológica. Isso não por desconhecimento, mas por trabalharem dentro dos limites e interesses impostos pelo establishment. Segundo Naess (1993), já é hora dos ecologistas profissionais expressarem suas preocupações plenamente ("profundamente", como apregoa a Ecologia Profunda). Uma Ecologia Superficial, voltada para a conservação de recursos naturais, pode ser algo limitador. Naess (1995) critica algumas ONGs conservacionistas e o programa das Nações Unidas para o Meio Ambiente (PNUMA) por basearem seus argumentos exclusivamente em termos da saúde e bem-estar humanos. E isso, diz Naess (1993), é extremamente antropocêntrico. "Uma nova ética, abrangendo plantas e animais, bem como pessoas, é requisito para que as sociedades humanas vivam em harmonia com o mundo natural do qual dependem para sobrevivência de seu bem estar [sic]" (NAESS, 1993, p.196). Mas o alpinista e ecofilósofo adverte: essa ética ambiental seria muito melhor implementada por aqueles que amam a Natureza do que simplesmente pelo interesse em ter um instrumento para a sobrevivência humana. Isso pode soar como antiacadêmico, diz Naess (1993), mas no momento em que a plataforma dessa nova ética é exposta, podemos realizar uma educação ambiental promovendo ambos os aspectos - o superficial e o profundo. A plataforma da Ecologia Profunda é composta por oito princípios que trariam a possibilidade de comunhão de abordagens. Em seu artigo de 1973, eram dezoito princípios, mas 
visando simplificar e abranger um público maior, Naess reduziu para oito os princípios da plataforma da Ecologia Profunda. Esses princípios partem de uma base comum: Naess defende o igualitarismo biosférico, ou seja, não há uma hierarquia de valor entre as diferentes entidades da ecosfera (biosfera) - rochas, plantas, animais, rios, seres humanos e a terra como um todo -, elas têm o mesmo valor. Todas essas entidades são iguais, pelo menos do ponto de vista ético. Sessions (1995) traça um panorama preliminar das origens do movimento da Ecologia Profunda:

As raízes filosóficas do movimento da Ecologia Profunda são encontradas no ecocentrismo de Henry David Thoureau, John Muir, D.H. Lawrence, Robison Jeffers, e Aldous Huxley. Abordagens sociais / ecológicas têm sido derivadas das críticas de George Orwell e Theodore Roszak, e das críticas dos problemas criados pelo surgimento das civilizações, escritas pelo historiador dissidente Lewis Mumford. Mais inspiração para a consciência ecológica contemporânea e o movimento da Ecologia Profunda pode ser encontrada nas religiões ecocêntricas e modos de vida primitivos de pessoas em todo mundo, do Taoísmo e São Francisco de Assis. A orientação romântica dada à Natureza pelo movimento contracultural do século dezenove com raízes em Spinoza, no Zenbudismo de Alan Watts e Gary Snyder (com influência de muitos ecologistas profissionais bem como do movimento contracultural dos anos de $1960(\mathrm{x}) .^{2}$

Existem grandes diferenças entre a Ecologia Profunda e a Ecologia Superficial. Para os ecologistas profundos, confiar simplesmente nos "interesses humanos", como faz a Ecologia Superficial, cria uma abordagem que apresenta sérios perigos, um deles são as intermináveis discussões técnicas entre experts sobre o que fazer, e em geral isso é feito em um jargão técnico que poucos são capazes de compreender, paralisando, assim, ações e políticas efetivas. A Ecologia Superficial se preocupa excessivamente com os aspectos econômicos. Já os ecologistas profundos pautam suas ações por uma visão de mundo formada a partir da filosofia e da religião e questionam os pressupostos das abordagens econômicas ou economicistas predominantes. Em última análise, as políticas

\footnotetext{
2 Para uma excelente análise do papel do romantismo e da contracultura na Ecologia e na Educação Ambiental, ver: CARVALHO, I.C.M. A Invenção Ecológica: Narrativas e

Trajetórias da Educação Ambiental no Brasil. Porto Alegre: Editora da Universidade/UFRGS, 2001.
} 
ambientais e ações dos ecologistas profundos fundamentam-se no valor intrínseco da natureza, ao passo que as abordagens dos ecologistas superficiais se baseiam no interesse e bem-estar humanos e, quase conseqüentemente, na economia. Mas deve se salientar que a Ecologia Profunda sabe como atuar em bases conflitantes ou contraditórias. Para exemplificar isso, Naess (1993) comenta sua afinidade com a Ecosofia T. De acordo com Naess (1993), todo mundo tem uma filosofia, mesmo que pareça não ter. Basta um questionamento arguto e a pessoa, mais cedo ou mais tarde, revela o que pensa em termos de vida e morte. "A Ecosofia T tem uma única norma: auto-realização” (NAESS, 1993, p.209). A concepção do eu (self) de Naess (1993) tem suas raízes nas tradições orientais do atma e o Auto (Self) com letra maiúscula visa abarcar todas as formas de vida do planeta, ou seja, todas as entidades do planeta têm direito à sua Auto-realização. Evidente que Arne Naess não está aqui falando de "ego". Em uma palavra, trata-se de "maximizar (o longo alcance, universal) da Autorealização" (p. 209). Isso implica maximizar todas as formas de vida (vida aqui é tomada em um sentido amplo e inclui águas e rochas). Na verdade, Naess (1993) advoga um certo tipo de Altruísmo, que começa na medida em que você vai se identificando com o outro pedras, rios, animais, plantas e humanos. Se você consegue maximizar sua própria Auto-realização, é porque sua identificação com outros seres está aumentando e isso deve levar o ecologista profundo a uma mudança nos estilos de vida, mas Naess (1993) diz que isso varia muito conforme a parte do mundo em que se está.

Tanto os trabalhos pioneiros de Routley (2003) e Naess (1973) como os debates que se seguiram ao longo dos anos de 1970 contribuíram para a consolidação da disciplina de Ética Ambiental em Universidades da Noruega, Austrália e Estados Unidos. No ano de 1979, o filósofo ambiental Eugene Hargrove fundou aquele que viria a ser o periódico mais prestigiado no campo da ética ambiental, o Environmental Ethics. Nos anos de 1980, a ética ambiental se disseminou por várias partes do mundo. Os anos oitenta foram caracterizados pela chegada da Ecologia Profunda nos Estados Unidos e no Canadá, período esse denominado de Atlantic Cross. A principal meta ainda é a estabelecida por Naess (1973) e Routley (1973), porém, com outras elaborações. Mas tratase ainda de fazer face ao desafio do antropocentrismo e de 
estabelecer uma ou várias teorias do valor intrínseco da Natureza. Quase todas essas teorias visavam combater as éticas e lógicas utilitaristas. Routley (2003) já argumentava que o chauvinismo humano das tradições éticas dominantes, entre elas a utilitária, concedia apenas valor instrumental para as entidades naturais nãohumanas (plantas e animais) e para a Natureza como um todo.

Pouco depois, Rolston (1975) dizia que uma Ética propriamente ecológica deveria perguntar pelo valor na natureza e não simplesmente pelo valor da natureza. Tom Regan (1981) iria fazer a distinção entre uma ética para o uso do meio ambiente e uma Ética do meio ambiente (uma ética genuína e não uma ética gerencial). Regan também se encarregaria de desenvolver o hoje clássico postulado do valor inerente na natureza: "O desenvolvimento do que poderia propriamente ser chamado de uma Ética Ambiental requer o postulado do valor inerente na natureza" (p.34) (GRÜN, 1994, p.184).

\section{Ética da Terra baseada no valor intrínseco da Natureza}

Holmes Rolston III é um dos mais influentes filósofos ambientais do valor intrínseco da Natureza. Ele se queixa que a Natureza tem sido tratada quase exclusivamente como um recurso natural e afirma que uma Educação Ambiental deveria nos ajudar a valorizar uma Natureza não consumida. A mudança radical ocorreria quando as pessoas, governos e empresas parassem de valorizar tanto os recursos e passassem a admirar mais "a Natureza em seus próprios termos" e não a perturbassem nem a desvalorizassem tanto. Isso não quer dizer que uma pequena parte da Natureza não possa ser transformada em recurso, mas teríamos de aprender a não valorizar somente os recursos e sim toda uma parte da Natureza que aparentemente não tem valor. Nós valorizamos apenas aquilo que processamos - madeira, água represada, minérios, etc -, deixando de lado o valor intrínseco da Natureza. A nossa civilização Ocidental parece ser capaz de conferir apenas valor instrumental à Natureza, valor de uso e de negociação. Simplesmente, não concebemos que uma enorme área da Natureza pode não servir ao mero interesse utilitário da maioria dos seres humanos. Para Rolston (1993), a afirmação "tudo é recurso" encontra paralelo na sentença "todo mundo é egoísta". As ações das pessoas estão baseadas no interesse e no benefício próprio. 
Nosso lugar no mundo natural necessita de relações com recursos, mas então chegamos num ponto em que queremos saber como nós pertencemos a este mundo, e não como o mundo pertence a nós. Nós queremos ter nossos selfs definidos em relação à Natureza, e não simplesmente definir a Natureza em relação a nós" (ROLSTON, 1993, p.57).

Se quisermos vencer "o paradigma da natureza-como-merorecurso-natural nós precisaremos de uma teoria do valor mais abrangente, uma teoria não-antropocêntrica" (idem, p.64). Para Rolston (1993), as pessoas contam, mas não tanto que nada mais conte. Rolston (1996) dá o exemplo de uma árvore. Árvores não têm vida subjetiva ou razão e são sistemas automantidos que se sustentam, se reproduzem e tentam executar os seus programas. A árvore tem um telos e busca cumpri-lo na realização de suas funções projetivas. Quando ferimos uma árvore, ela tenta, de todas as maneiras que lhe são possíveis, se regenerar. Ela está sempre procurando um estado de valor. Todo organismo possui o bem-desua-classe e a ela defende como uma classe boa. De modo semelhante, Rolston estende essa argumentação do valor em si dos organismos, animais superiores e inferiores, para espécies e ecossistemas e, finalmente, para a Terra como um todo (GRÜN, 1994).

Recentemente, Rolston (2003) surpreendeu a comunidade internacional de ambientalistas, educadores e filósofos ambientais ao afirmar que, quando ocorresse um antagonismo radical entre Salvar a Natureza ou Alimentar as pessoas, deveríamos deixar que as pessoas morressem, pois a diversidade de lugares como a floresta Amazônica e Madagascar não poderia ser sacrificada. O texto provocou grande polêmica. Em Grün (1998), respondi a Rolston, dizendo que é preciso, antes de mais nada, reverter o processo de desorganização socioambiental da Amazônia. E a "reversão do processo de desorganização socioambiental da Amazônia só pode ser alcançada por meio de promoção de dinâmicas sócio-políticas [sic] que se anteponham às práticas técnicas e econômicas responsáveis pela predação" (ACSEBRAD apud GRÜN, 1998). A dicotomia de Rolston (2003), Pessoas Famintas versus Natureza, não dá conta disso. 


\section{As fundações conceituais da Ética da Terra de Baird Callicott}

Callicott $(1989,1993)$ é outro dos mais influentes filósofos ambientais. Ele desenvolve sua Ética da Terra principalmente a partir do conservacionista e guarda florestal Aldo Leopold e seu livro A Sand County Almanac and Sketches Here and There, mas também utilizando os trabalhos de Charles Darwin, David Hume e Adam Smith. A Ética da Terra de Leopold tem encontrado muitos seguidores, mas também muitos críticos, como John Passmore, Jim McCloskey e Robin Attfield ${ }^{3}$. Callicott (1993) se defende dizendo que a ética da terra ${ }^{4}$ de Leopold, na qual se baseia para formular a sua própria ética, tem sido mal interpretada como uma ética nobre, porém muito ingênua. Além disso, o próprio Callicott (1993) reconhece que ela não é familiar e soa radical demais. No entanto, complementa o autor, trata-se de uma teoria moral revolucionária. Uma das críticas à ética da terra de Leopold é que o mundo está ruim demais para aceitar a nossa participação ética na natureza. Callicott (1993) se defende dizendo que a moralidade não é descritiva, e sim prescritiva ou normativa. Além do mais, nunca a nossa história (ocidental) apresentou tantos e diversos movimentos que têm argumentado em uma base moral: direitos humanos, feminismo, animal liberation, que são uma espécie de extensão da ética. Essa extensão é vista por Leopold (1987) como uma evolução ecológica. Callicott (1993) argumenta que Darwin já via o fenômeno ético como evolucionário e Hume e Adam Smith, por sua vez, acreditavam que a ética estava ligada aos sentimentos. As sementes da ética da terra de Leopold estão em Darwin e parecem começar por um sentimento que talvez seja comum a todos os mamíferos - sentimento de união e até afetividade entre pais e sua prole. Essas relações de "sentimentos sociais", diz Darwin, acabam se tornando mais difusas e se disseminam por populações formando comunidades e tornando esta comunidade e seus

3 PASSMORE, J. Man's Responsability for Nature: Ecological Problems and Western traditions. New York: Charles Scribner's Sons, 1974.

MCCLOSKEY, H.J. Ecological Ethics and Politics. New Jersey: Rowman and Littfield, 1983.

ATTFIELD, R. Value in the Wilderness. Metaphilosophy 15 (1984).

${ }^{4}$ Ética da terra está em minúsculo porque é como Aldo Leopold a apresenta (land e não earth). 
membros mais resistentes. A leitura que Aldo Leopold faz de Darwin permite que ele estabeleça o protoprincípio de sua ética da terra: o de que a ética tem sua origem remota na tendência de indivíduos interdependentes ou grupos evoluírem por meio da cooperação. Para Leopold (1987), toda e qualquer ética se baseia no princípio de que o individuo é um membro de uma comunidade de partes interdependentes. Essa é a gênese da ética da terra de Aldo Leopold (CALLICOTT, 1993). Leopold (1987) considera "ética, sociedade e comunidade" como quase sinônimos. Mais tarde, ele vai desenvolver isso em termos de modo de pertença de um indivíduo à terra. Evidentemente, trata-se de uma postura ecocêntrica que se pretende radical. Esse sentimento de pertença pode também ser encontrado em muitas pessoas que, por exemplo, advogam que todos os membros da espécie humana (como membros da humanidade, uma comunidade) têm direitos fundamentais independente de raça, credo, etnia, sexo ou origem nacional. Mas de acordo com Leopold (1987) a ética humana universal é incompleta, falta a noção de comunidade e, por extensão, a de terra. Falta à ética universal humana um modo de pertença dos humanos a algo maior que eles/elas e que deveriam aprender a respeitar. "A ética da terra simplesmente alarga os laços da comunidade para incluir solos, águas, plantas e animais, ou coletivamente: a terra" (LEOPOLD apud CALLICOTT, 1993, p.389). Ou seja, para Leopold, a terra é uma comunidade. O conceito de comunidade biótica foi desenvolvido por Charles Elton nos anos de 1920. "A chave para a emergência de uma ética da terra é, simplesmente, educação ambiental universal" (CALLICOTT, 1993, p.389).

O conceito de comunidade visa integrar socialmente as entidades não-humanas com as humanas. Callicott (1993) acredita que a teoria Copernicana também pode ilustrar nossa situação de comunidade no espaço sideral. A Terra é vista hoje apenas como um pequeno planeta rodeado por um universo imenso e hostil e isso pode reforçar nossa noção de comunidade. Goodpaster, citado em Callicott (1993), diz que Leopold conseguiu estabelecer a considerabilidade moral não apenas para os membros da comunidade biótica, mas da comunidade biótica propriamente. Afinal, Leopold diz claramente que o Homo Sapiens deve abandonar seu papel de conquistador da terra e tornar-se um membro e cidadão 
da comunidade-terra e, mediante essa pertença, Leopold (1987) estabelece a máxima moral da ética da terra: "uma coisa é correta quando tende a preservar a integridade, estabilidade e beleza de uma comunidade biótica. Está errada quando tenta o contrário" (citado em CALLICOT'T, 1993). Há também um componente estético no modo de pertença do humano à comunidade biótica. A sensibilidade moral, embora seja resultado da evolução, não é determinada por ela. A sensibilidade ou os sentimentos morais são fruto da ecologia, seguindo o modelo de comunidade de Charles Elton. A idéia de ecossistema de Tansley também se revelou um conceito muito fértil para a ética da terra. Poderíamos ser levados aqui a pensar na teoria Gaia; no entanto, Leopold abandona a idéia de modelo-organismo ou superorganismo, ficando com o conceito de comunidade. Para Tansley, "a energia solar se transmite através de um circuito chamado biota". Defender essa integridade da complexa estrutura da terra é tarefa moral de todos os membros da comunidade. A ética da terra não partilha dos pressupostos do racionalismo Ocidental, mas dos sentimentos morais de Hume e Darwin: amor, respeito, obrigação e admiração.

As éticas ambientais de Routley (2003), Naess (1995), Rolston $(1993,1996)$ e Callicott $(1989,1993)$, que apregoam o valor intrínseco da Natureza, têm muitas diferenças entre si nas suas formulações e aplicações. Mas têm também muitos pontos convergentes, como, por exemplo, a crítica ao valor instrumental da Natureza. Essa crítica, quando vista pelo diversificado prisma da Educação Ambiental, adquire múltiplas facetas. A principal, a meu ver, é a crítica à racionalidade econômica dominante. $\mathrm{O}$ racionalismo econômico ou neoliberalismo se torna impraticável em uma política ambiental que enfatize o valor intrínseco da Natureza. Afinal, não podemos considerar a Natureza como mero recurso natural. Quando fizermos isso, estaremos apenas defendendo as condições de produção do novo capitalismo e a felicidade humana de muito poucos. Esse é um dos equívocos centrais de algumas posturas de Desenvolvimento Sustentado, conceito este que, por sua vez, também é redefinido quando pensamos em valor intrínseco. Por meio de valores intrínsecos da Natureza, que não podem ser simplesmente comprados ou meramente instrumentalizados, a Educação Ambiental é redimensionada em sua capacidade de trabalhar com valores. Outro insight das éticas 
ambientais é de que os valores intrínsecos da Natureza podem ser úteis à Educação Ambiental também na crítica do ecofeminismo às relações patriarcais estabelecidas pelo domínio dos homens, brancos e capitalistas sobre a Natureza. Salleh (1993), por exemplo, acredita que as "relações" que o patriarcado estabelece com a Natureza são de controle, ao passo que as mulheres historicamente teriam uma postura de reciprocidade. Plumwood (1993) faz uma contextualização cultural de Salleh (1993). Ela argumenta que a tradição racionalista e masculinista Ocidental dominante não valorizou moralmente conceitos como respeito, afinidade, cuidado, preocupação, compaixão, gratidão e amizade, conceitos estes que pertenciam à esfera privada da mulher, e não ao reino universal da razão legisladora.

\section{Pluralismo Moral e Monismo Moral}

Nos anos de 1990, assistimos ao nascimento de mais um prestigiado periódico de ética ambiental, o Environmental Value, na Inglaterra. Nessa época, as éticas ambientais chegaram a um tal grau de diversificação que muitos teóricos começaram a se perguntar se apenas uma ética e um determinado conjunto de princípios seriam suficientes para desencadear uma Educação Ambiental e dar conta da complexidade das questões ambientais. Surgiram, então, os pluralistas morais - Christopher D. Stone, Andrew Brennan, Peter Wenz $z^{5}$. Mas logo após, em 1994, Callicott se definiu como Monista e disse que uma ética ambiental Monista poderia também ser sensível à complexidade dos problemas ambientais sem cair na promiscuidade moral dos pluralistas. Callicott (2003) argumenta que nada impede que ambientalistas, educadores e teóricos mal intencionados simplesmente troquem de teoria para teoria com intuito de receber benefícios pessoais.

Em Earth and Other Ethics: the case for moral pluralism (A Terra e Outras Éticas: o caso para o pluralismo moral) e The Case of Moral Pluralism in the Course of Environmental Ethic (O Caso do Pluralismo

5 STONE, C.D. Earth and Other Ethics. BRENNAN, A. Thinking about Nature. WENZ, P. Minimal, Moderate, and Extreme Moral Pluralism. In: LIGHT, A. and ROLSTON III, H. (Eds.). Environmental Ethics: an anthology. Malden: Blackwell Publishing, 2003. 
Moral no Curso da Ética Ambiental), Stone (1987, 2003) defende o pluralismo moral e pergunta se realmente deveríamos adotar princípios morais invariantes para fazer o campo da ética ambiental progredir. Na verdade, o debate entre Monismo e Pluralismo Moral parece ter se revelado um locus privilegiado para a discussão sobre qual o papel da metaética no campo mais amplo da moral. Para Stone (2003), está claro que a metaética ortodoxa tem um "senso de missão". "É amplamente presumido, por implicação quando não é tornado explícito, que a tarefa da ética é promover e defender um único princípio (ou um corpo coerente de princípios) (...)" (STONE, 2003, p. 195). Um ponto de vista correto que nos guiasse em direção a uma solução correta. Mas o autor adverte que os ambientalistas e educadores (as) têm boas razões para suspeitar do Monismo, pois enfrentam sempre uma variedade de situações muito complexas para que sejam analisadas a partir de uma matriz ética única. Uma matriz ética Monista pode funcionar bem quando aplicada às relações entre pessoas, ou seja, uma ética intra-humana, como dizia Routley (2003). Seria uma ética do tipo "deves respeitar as outras pessoas", uma ética facilmente generalizável. Mas ela colapsa quando entidades mais exóticas são analisadas moralmente, como, por exemplo, a consideração moral pelas futuras gerações, embriões, animais, árvores, robôs, montanhas e obras de arte. Stone (2003) argumenta que, em geral, o que acontece nesses casos é uma extensão da ética intra-humana para entidades não-humanas. No entanto, esses argumentos parecem "forçar" a considerabilidade moral simplesmente colocando entidades nãohumanas no lugar de pessoas. A pergunta que se coloca é: Pode uma moralidade operar por intermédio de uma diversidade de entidades não-humanas? Precisamos nós de um único conjunto de princípios abstratos generalizáveis a todo mundo não-humano? $\mathrm{O}$ próprio Stone (2003) responde dizendo que as "ambições do Monismo de unificar toda ética dentro de uma estrutura capaz de afirmar uma resposta correta para todos os nossos dilemas são simplesmente quixotescas" (p.196). A moralidade envolve distintas atividades e uma variedade de coisas e o Pluralismo Moral dá conta disso, nos convidando a escolher diferentes estruturas conceituais. Steen, citado em Stone (2003), comenta que mesmo a matemática sofreu um processo de pluralização desde Gödel e onde uma vez 
havia a geometria, hoje encontramos geometrias, onde havia álgebra, temos álgebras.

A ética tem como seu objetivo escolher a ação certa. Enquanto o Monismo Moral escolhe uma ação correta sempre sob a égide dos mesmos princípios, o Pluralismo Moral analisa qual pode ser a ação ética coerente por muitos ângulos possíveis. Stone (2003) não poupa os monistas e sugere que os que preferem uma única avaliação moral são "moralistas". Comparar alternativas é algo lógico. Tomemos como exemplo um caso clássico da literatura em ética ambiental: o de um búfalo se afogando em um rio de um Parque Nacional. Deveríamos salvá-lo ou deixar que a Natureza tome seu curso? Um dos pontos de vista favorece o animal. Mas há ainda a considerabilidade moral que favorece o ecossistema do parque e outra ainda que favorece a espécie. Isso provoca uma constelação de conceitos. A análise moral do animal leva em conta: dor, inteligência, compreensão da situação, ao passo que o foco no ecossistema considera moralmente a estabilidade, resistência, singularidade e fluxo de energia. São $n$ variáveis a serem levadas em conta na análise moral. Não existe uma única solução. Nós estamos sempre atravessando fronteiras morais de um domínio para o outro; dos animais para organismos vivos, destes para ecossistemas e espécies e ainda destes para a Terra ou a biodiversidade, grupos culturais, gerações futuras, povos indígenas, aquecimento global, etc. Em Educação Ambiental, o Pluralismo Moral pode ser útil no sentido de saber o que estamos valorizando e avaliando, protegendo ou criticando em cada caso.

Já o Monista J.Baird Callicott (2003) se defende das acusações de Stone (2003) dizendo que o Pluralismo leva qualquer teoria ética a um ponto de ruptura e assim somos deixados com apenas duas alternativas: o cinismo moral ou o pluralismo moral. Callicott (2003) não adere a nenhum desses dois caminhos e diz que atualmente existe um número impressionante de teorias éticas bem fundamentadas capazes de ser suficientemente inclusivas para abrigar várias preocupações de cunho ético. Callicott (2003) cita sua própria teoria, o altruísmo presente em Hume e Darwin, para advogar que uma teoria inclusiva é possível. Também faz menção à Ética da Terra de Rolston (1996) e à Ecosofia T. de Arne Naess (1995) como exemplos de teorias que dão conta da diversidade, dos contextos e da variedade de problemas socioambientais. Callicott 
(2003) critica o Pluralismo Moral ilustrando como ele seria em nossas vidas diárias. O pluralismo moral nos convidaria a ter uma atitude moral com os amigos, outra com os vizinhos, outra como cidadãos, outra para ajudar nosso filho no dever de casa, ainda outra para com as futuras gerações, outra para as nossas relações com o mundo animal não-humano, outra para as plantas, outra para Gaia e assim ad infinitum. Isso levaria à promiscuidade moral. Ao invés disso, argumenta Callicott (2003), teríamos de insistir nas possibilidades oferecidas por uma abrangente metaética. Essa ética teria que dar conta não só das relações humanas, mas também das relações humanas com as entidades naturais não-humanas e com a Terra como um todo. Uma ética desse tipo fornece possibilidades para a Educação Ambiental compreender os problemas socioambientais de um modo holístico e integrado, não fragmentado como o Pluralismo Moral.

\section{Ética Ambiental da Ecologia Social}

À primeira vista, uma ética ambiental crítica poderia facilmente levar o leitor(a) à conclusão de que os problemas ecológicos só receberiam atenção depois que vivêssemos em uma sociedade igualitária e justa. Mas nada poderia estar mais longe da realidade da Ecologia Social de Murray Bookchim (1995), adverte o filósofo ambiental anarquista John Clark. Nós (humanos) seríamos a Natureza conhecendo a si própria, uma segunda Natureza.

Ao afirmar esse naturalismo dialético, a ecologia social rejeita as divisões sociais e as ideologias dualísticas que têm sido centrais para a dominação tanto da humanidade como da natureza. Em oposição ao dualismo da sociedade hierárquica, a ecologia social propõe um princípio de totalidade ecológica que vê todo curso da evolução planetária como um processo objetivando um aumento da diversidade e a emergência do valor (CLARK, 1993, p. 345).

Não há separação entre a dominação da Natureza e dominação dos humanos uns pelos outros, pois nós somos Natureza. Ao se transformar uma sociedade humana por meio da consciência ecológica, a interação da humanidade com a Natureza também será transformada. O fato de a humanidade ser a "natureza tornada auto-consciente [sic]" acarreta várias implicações de cunho 
ético: "isso significa que nós pensamos como energia autoconsciente, vida auto-consciente, animal auto-consciente, terra auto-consciente" (CLARK, 1993, p. 346-347). A liberdade se encontraria na autodeterminação e na cooperação simbiótica de todos os níveis. A Ecologia Social é holista, pois a Terra é vista como um todo do qual todos os seres são partes. A realização do bem da Terra enquanto totalidade geradora de valor é inseparável do autodesenvolvimento advindo de nossa cooperação com a evolução. A regeneração ecológica é inseparável da regeneração social e da criação de ecocomunidades. O capitalismo e o estado tecnoburocrático seriam então substituídos por comunidades. Bookchim (1995) argumenta, seguindo Kropotkin, que as novas formas sociais que emergirão enfatizam o ideal da unidade na diversidade. Trata-se do comunitarismo libertário. O fato de Bookchim (1995) nos considerar "natureza" recupera uma antiga tradição - a do zoon politikon, o homem como animal político - e cria um novo espaço público, diz Clark (1993). A democracia seria do tipo face a face. Para isso, os ecocomunitaristas promoveriam assembléias da cidade ou da vizinhança. ${ }^{6}$ A noção de cidadania é fundamental para Bookchim (1995). "A meta a longo prazo é a substituição do capitalismo hierárquico e da organização estatista por uma confederação de comunidades ecológicas - a curto prazo, por uma democracia ecológica" (CLARK, 1993, p.350).

\section{Recentes Desenvolvimentos da Ética Ambiental}

Após quase quarenta anos da publicação dos primeiros trabalhos de ética ambiental, podemos dizer que vários avanços foram feitos. As teorias do valor intrínseco da Natureza se diversificaram. As discussões entre Monismo Moral e Pluralismo tomaram maior dimensão e as propostas do bioigualitarismo se tornaram mais plurais, incorporando aspectos das filosofias da diferença como classe, etnia, raça, gênero e nacionalidade. Como diz Fox (1993), não há nenhum problema em admitir que os maiores dominadores do mundo são os homens, ocidentais,

${ }^{6}$ O Brasil já tem experiências nesse tipo de discussão. Um exemplo é a cidade de Porto Alegre, onde durante dezesseis anos ocorreu o orçamento participativo. Hoje, graças a essa experiência, Porto Alegre é a única cidade no Brasil com 100\% de saneamento básico. 
brancos e capitalistas, contanto que não se fique cego para aquela que é a dominação maior: o antropocentrismo. Kovel (1993) chega a falar em um "casamento" entre ecologias radicais e acredita que não podemos nos contentar com uma ética ambiental meramente "reformista", mas sim questionar radicalmente as ordens sociais que criaram os problemas ecológicos. $\mathrm{O}$ capitalismo precisaria ser visto como algo mais que um sistema econômico, como uma economização da realidade humana, e é preciso perceber que a dominação da Natureza não ocorre sem a dominação de humanos sobre outros humanos. Atualmente, podemos assistir a um flerte profícuo entre ecologias radicais que criticam o antropocentrismo exacerbado da cultura ocidental e aquelas que são críticas das dominações de classe, raça, etnia e gênero (CUOMO, 1998). Vários desenvolvimentos recentes da ética ambiental têm apontado para uma ênfase no Multiculturalismo com abordagens éticas ambientais indígenas, budistas, taoístas e islâmicas. As relações entre ética ambiental e Educação Ambiental também começam a surgir Grün (2006, 2007), Flickinger (1994) e muitos outros. O livro Pensar o ambiente: as bases filosóficas da Educação Ambiental é um passo importante no que se refere a estabelecer conexões entre a Educação Ambiental e a Filosofia Ambiental, traz textos de filósofos, psicanalistas e educadores(as) ambientais que vão desde os Pré-Socráticos até Heidegger, Vigotsky, Paulo Freire e outros. Além disso, o livro Em Busca da Dimensão Ética da Educação Ambiental (GRÜN, 1997, no prelo) propõe uma ética de parceria com a Natureza em Educação Ambiental baseando-se na filosofia hermenêutica de Gadamer e na crítica ao Cartesianismo. $\mathrm{O}$ amplo leque de éticas ambientais dá testemunho de uma grande diversidade de pensamentos e vem ao encontro da também muito diversificada educação ambiental. As éticas ambientais têm um enorme potencial subversivo, pois não aceitam o status quo que tornou parte da humanidade dominadora da Natureza e, em conseqüência, não aceitam também a ordem social vigente. Creio que quanto mais uma ética ambiental for capaz de estabelecer conexões com uma práxis transformadora, mais facilmente ela terá

${ }^{7}$ CARVALHO, I.C.M; GRÜN, M.; TRAJBER, R. (Orgs.). Pensar o Ambiente: bases filosóficas da Educação Ambiental. Brasília: Ministério da Educação e Cultura, 2007 (no prelo). 
condições de nos empoderar para que estejamos alertas para tudo aquilo que se apropria de nós ou da Natureza sem o nosso consentimento.

\section{Referências bibliográficas}

BOOKCHIN, M. The Philosophy of Social Ecology: essays on dialectical naturalism. Montrèal: Black Rose Books, 1995.

CALLICOTT, J.B. The Conceptual Foundations of the Land Ethic. In: ARMSTRONG, S.J. and BOTZLER, R.G.(Orgs.). Environmental Ethics: divergence and convergence. New York: McGraw-Hill, 1993.

. In Defense of the Land Ethic: essays on environmental philosophy. New York: Suny Press, 1989.

. The Case against moral Pluralism. In: LIGHT, A. and ROLSTON III, H. (Eds.). Environmental Ethics: an anthology. Malden: Blackwell Publishing, 2003.

CARVALHO, I.C.M. A Invenção Ecológica: Narrativas e Trajetórias da Educação Ambiental no Brasil. Porto Alegre: Editora da Universidade / UFRGS, 2001.

CLARK, J. Introduction. In: ZIMMERMAN, M.E. et al. (Eds.). Environmental Philosophy: From Animal Rights to Radical Ecology. New Jersey: Prentice Hall, 1993.

CUOMO, C.J. Feminism and Ecological Communities: an ethic of flourishing. New York: Routledge, 1998.

FOX, W. The Deep Ecology-Ecofeminism Debate and Its Parallels. In: ZIMMERMAN, M.E. et al. (Eds.). Environmental Philosophy: From Animal Rights to Radical Ecology. New Jersey: Prentice Hall, 1993.

GRÜN, M. Uma discussão sobre os valores éticos em Educação Ambiental. Educação e Realidade. v.19, n.2, jul./dez. 1994. mar. 1998. Pessoas famintas versus natureza. Políticas Ambientais, n. 16, dez. 1997/ Educação e Ética Ambiental: a conexão necessária. $10^{\mathrm{a}}$ ed. Campinas: Papirus, 2006. 
. Em Busca da Dimensão Ética da Educação Ambiental. Campinas: Papirus, 2007 (no prelo).

KOVEL, J. The Marriage of Radical Ecologies. In: ZIMMERMAN, M.E. et al. (Eds.). Environmental Philosophy: From Animal Rights to Radical Ecology. New Jersey: Prentice Hall, 1993.

LEOPOLD, A. A Sand County Almanac and Sketches Here and There. New York: Oxford University Press, 1987.

LIGHT, A. and ROLSTON III, H. (Eds.). Environmental Ethics: an anthology. Malden: Blackwell Publishing, 2003.

NAESS, A. Ecology, community and lifestyle. New York: Cambridge University Press, 1995.

. The Deep Ecological Movement: Some Philosophical Aspects. In: ZIMMERMAN, Michael E. et al. (Eds.). Environmental Philosophy: From Animal Rights to Radical Ecology. New Jersey: Prentice Hall, 1993.

PLUMWOOD, V. Feminism and the Mastery of Nature. New York: Routledge, 1993.

Paths Beyond Human-Centeredness: Lessons from Liberation Struggles. In: WESTON, Anthony (Ed.). An Invitation to Environmental Philosophy. New York: Oxford University Press, 1999.

REGAM, T. The nature and possibility of environmental ethic. Environmental Ethics, Denton, v.3, 1981.

ROLSTON III, H. Is there an ecological ethic? Ethics, v. 85, 1975.

Values Gone Wild. In: ARMSTRONG, S.J. and BOTZLER, R.G.(Orgs.). Environmental Ethics: divergence and convergence. New York: McGraw-Hill, 1993.

. Earth Ethics: a challenge to liberal education. In: CALLICOTT, J.B. and ROCHA, F.J.R. (Eds.). Earth Summit Ethics: Toward a Reconsttructive Postmodern Philosophy of Environmental Education. New York, Suny Press, 1996.

Feeding People versus Saving Nature? In: LIGHT, A. and ROLSTON

III, H. (Eds.). Environmental Ethics: an anthology. Malden: Blackwell Publishing, 2003. 
ROUTLEY, R.S. Is There a Need for a New, an Environmental, Ethic? In: LIGHT, A. and ROLSTON III, H. (Eds.). Environmental Ethics: an anthology. Malden: Blackwell Publishing, 2003.

SESSIONS, G. (Ed.). Deep Ecology for the 21 $1^{\text {st }}$ Century: readings on the Philosophy and Practice of the New Environmentalism. Boston: Shambala, 1995.

STONE, C.D. Earth and Other Ethics: the case for moral pluralism. New York: Harper \& Row, 1987.

Moral Pluralism and the Course of Environmental Ethics. In: LIGHT, A. and ROLSTON III, H. (Eds.). Environmental Ethics: an anthology. Malden: Blackwell Publishing, 2003. 
